Article

\title{
Sustainable Supply Chain Management: The Influence of Disposal Scenarios on the Environmental Impact of a 2400 L Waste Container
}

\author{
José Eduardo Galve ${ }^{1}$, Daniel Elduque ${ }^{2, *}$, Carmelo Pina ${ }^{1}$ and Carlos Javierre ${ }^{2}$ \\ 1 BSH Electrodomésticos España S.A.; Avda. de la Industria, 49, Zaragoza 50016, Spain; \\ jose.galve@bshg.com (J.E.G.); carmelo.pina@bshg.com (C.P.) \\ 2 i+(i3A), Department of Mechanical Engineering, University of Zaragoza; C/María de Luna, 3, \\ Zaragoza 50018, Spain; delduque@unizar.es (D.E.); carlos.javierre@unizar.es (C.J.) \\ * Correspondence: delduque@unizar.es; Tel.: +34-876-555-211; Fax: +34-976-761-861 \\ Academic Editor: Young Hae Lee \\ Received: 24 April 2016; Accepted: 12 June 2016; Published: 17 June 2016
}

\begin{abstract}
This paper analyzes the influence of the supply chain management on the environmental impact of a $2400 \mathrm{~L}$ waste disposal container used in most cities of Spain. The studied functional unit, a waste disposal container, made up mostly of plastic materials and a metallic structure, and manufactured in Madrid (Spain), is distributed to several cities at an average distance of $392 \mathrm{~km}$. A life cycle assessment of four different scenarios (SC) has been calculated with the software EcoTool v4.0 (version 4.0; i+: Zaragoza, Spain, 2015) and using Ecoinvent v3.0 database (version 3.0; Swiss Centre for Life Cycle Inventories: St. Gallen, Switzerland, 2013). The environmental impact has been characterized with two different methodologies, recipe and carbon footprint. In order to reduce the environmental impact, several end of life scenarios have been performed, analyzing the influence of the supply chain on a closed-looped system that increases recycling. Closed loop management of the waste and reuse of parts allows companies to stop selling products and start selling the service that their products give to the consumers.
\end{abstract}

Keywords: environmental impact; supply chain; service; LCA; end of life scenarios; closed loop; plastic recycling

\section{Introduction}

The analysis of different supply chain scenarios in order to increase competitive advantages of companies is currently an important research topic. A wide range of authors have analyzed how decisions related to supply chain management, such as returns policies, affect companies [1].

In the recent years, both supply chain and sustainability have raised a significant interest. Sustainable transport has a relevant issue: environmental impact [2]. The environmental impact of the supply chain is highly influenced by vehicle technology and operational decisions $[3,4]$. The relationships between supply chain decisions and environmental impact have been studied due the relevance of transport systems in sustainable development strategies, such as traffic policies [5], green innovation [6], or life cycle assessment (LCA) [7-9].

The topic of green supply chain management aims to integrate environmental concepts in supply chain management, reducing emissions, wastage and other forms of industrial pollution $[2,10,11]$. Several authors have researched on the relationships between the environmental impact of logistics, the product and the packaging. Supply chains are complex network where, for some products, factors like the packaging [12] , not only have a logistic role and influence on the effectiveness and efficiency of the supply chain [13], but may also have significant marketing and environmental influence [14]. 
Packaging has huge relevance in the retail supply chain, as shown in the literature in case studies from the consumer electronic goods industry [15] to large retail companies [16] or smaller food retail companies $[17,18]$. Several companies are implementing sustainable logistics to increase their supply chain competitiveness [19-21]. According to Leigh and Li, in order to develop environmental sustainable supply chains, approaches such as ecodesign, recycling, reuse or remanufacturing can be used [22-24].

LCA has become a very useful tool to study the impact of a product, a production process or a service throughout its entire lifespan. Results of these assessments can be used to establish, in a scientific way, the most critical aspects affecting the environmental impact of a wide range of products or services, like wind turbines [25], induction hobs [26,27], plastic recycling [28] or waste management [29].

In the study of a manufactured product, the impact will change depending on the materials and processes selected by the designers, transportations selected by supply chain managers, etc. [30]. This is the reason why LCA is being more often used during the early stages of a product's life cycle [31-33]. LCA focuses on the environmental pillar of sustainability [34]. The design methodology that includes the environmental factor is known as "ecodesign", and implies having into account the impact of each possible material, process used for the manufacturing [35], transportations and end of life scenarios. The designer will have to evaluate the environmental impact of raw materials, processes, transportations and weights as extra variables to the equations of the design process. At the same time, the logistic studies must have into account the impact due to the transportation chosen for both raw materials from the provider to the manufacturing site, the final product from the manufacturing site to the place in which it will be used, and also the recovery of the product if a closed loop supply chain network is used [36]. This strategy is one of the main opportunities of research in this field, as it can be applied to a wide range of industries [37] and contributes to achieve more eco-efficient production systems [36,38]. Closed loop supply chain can be used to create product service supply chains, including the return or disposal of the goods [38,39].

This closed loop strategies can be enhance with the use of emerging technologies such as RFID (Radio Frequency IDentification) tags enable producers to properly control the whole life cycle of a product, as they can be used to have item-level information visibility and instantaneous tracking during the manufacturing process, and also, years after, be used again in a recycling/remanufacturing scenario [40].

The aim of this paper is to analyze, from the environmental point of view, the life cycle of a large waste disposal container of $2400 \mathrm{~L}$ capacity (Figure 1), and the influence on the environment of supply chain management decisions by evaluating different disposal scenarios. We will also study how a closed loop system helps to reduce environmental impact by reusing or recycling some parts, or even the whole container. The effect of each disposal scenario given to the unit after the end of its service period will be studied in order to calculate the environmental impact and extract conclusions over the different decisions made during the supply chain management [41]. For this, four different scenarios will be proposed to see the differences and singularities amongst them. 


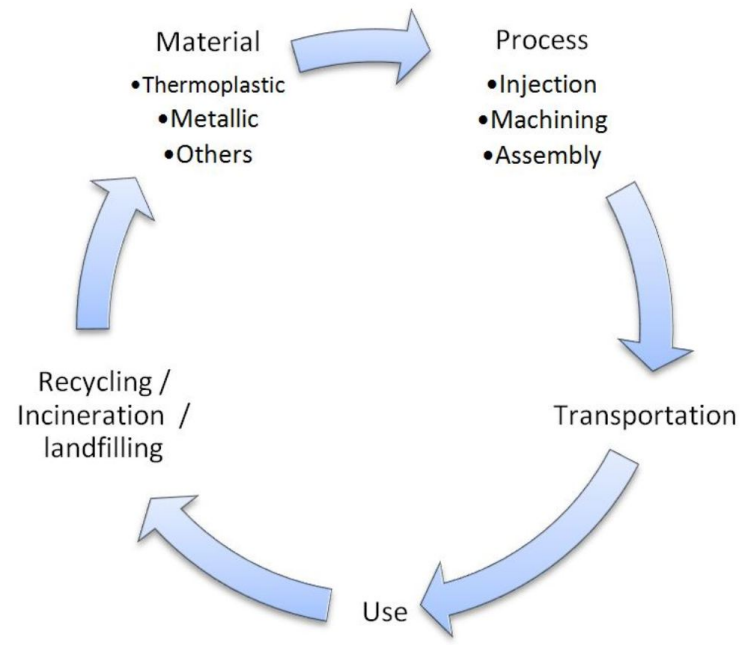

Figure 1. Life cycle.

\section{Materials and Methodology}

\subsection{Product under Study}

In this paper, a waste disposal container is going to be analyzed. The concept of waste disposal containers has varied through the time from small-sized metallic containers to bigger and more complex units combining metallic parts with advantages regarding costs and processability thanks to the use of plastic material. The manufacture of these plastic parts can be done well by injection molding, or by rotational molding [42]. Injection is a high pressure process, which is more stable and precise. It allows us to obtain great benefits regarding process stability and cost in high volume series. On the other hand, rotational molding is a slower low-pressure process with which the dimensional tolerances that are achieved are poorer. This study focuses on a large waste container of $2400 \mathrm{~L}$ which is widely used in Spain. There are several types of containers that are used in waste collection systems and they are usually made out of HDPE (High Density PolyEthylene), fiberglass or steel, with volumes ranging from 60 to $3200 \mathrm{~L}[29,43]$. One of the main targets of the design process of this waste container was to reduce the environmental impact, not only by considering the product but the whole life cycle. In order to do that, several strategies were used, such as minimizing as much as possible the use of metallic materials, which, compared to the plastic parts, are heavier and less flexible to the design, or optimizing the shape by modifying draft angles to increase the stackability of the containers and therefore the number of units that fit into a truck. Thanks to this stackability, there is no need for primary packaging to be transported. FEM (Finite Element Method) analysis was used to determine the optimal thickness to withstand all the requirements and at the at the same time reduce the amount of raw material consumption [42]. The weight will directly affect the environmental impact of the whole supply chain [19].

This product was also designed with the aim of reducing the number of different materials in order to simplify ulterior treatments. This facilitates and favors recycling or reusing processes. Also, unions between parts have been enhanced to ease disassembly and the stacking has been optimized to minimize the cost of the transportation to the end consumer and back to the manufacturer if a closed loop system is used. Selecting a single kind of thermoplastic material to the whole set favors both the cost and the separation and recycling of the elements after their usage period [44], optimizing the supply chain of the product.

The functional unit under study is a $2400 \mathrm{~L}$ waste disposal container used in most Spanish cities [42]. This waste disposal container comprises 37 different parts, which amount to a total number 
of 179 components and a weight of $139 \mathrm{~kg}$. Most of these components are made out of plastic, using mostly one single type (HDPE) for the main body and two upper lids (see Figure 2) or galvanized steel for the structural parts.

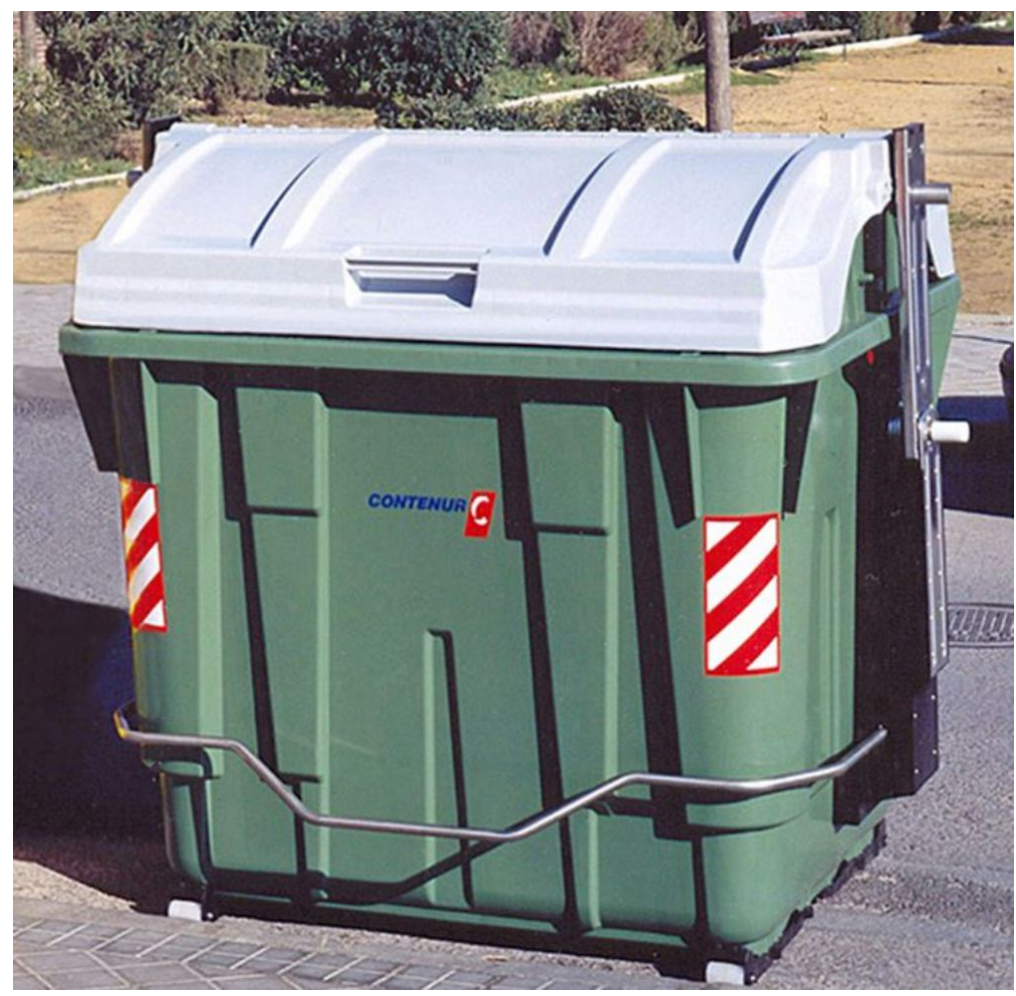

Figure 2. Waste disposal container.

Besides reducing the number of different raw materials used, a good definition of the unions and joints between different parts is also important. Separating the parts of an assembly is the previous step to re-using or recycling those components and must accrue as low costs as possible since it is a non-added value process.

A table with a simplified inventory is shown in order to provide better understanding of the paper and the functional unit under study (see Table 1). However, calculations were made with the full inventory of the waste container. Seventy seven percent of the overall weight of the container is HDPE.

Table 1. Simplified Inventory of a Waste Container.

\begin{tabular}{ccccc}
\hline Part & Material & Weight $\mathbf{( k g )}$ & Units & Total Weight $\mathbf{( k g )}$ \\
\hline Body & HDPE & 70.9 & 1 & 70.9 \\
Lid & HDPE & 7.5 & 2 & 15 \\
Axle & Steel & 7.1 & 1 & 7.1 \\
Lateral Holder & HDPE & 4.6 & 2 & 9.2 \\
Lateral reinforcement & Steel & 3.9 & 2 & 7.8 \\
Pedal & Steel & 2.2 & 1 & 2.2 \\
\hline
\end{tabular}

\subsection{System Boundaries}

This study takes into account the whole life cycle of the product, including raw materials acquisition (HDPE, steel, etc.), raw material transportation, processing and manufacturing (such 
as injection molding), distribution, use and end of life, considering in these last stages the waste container transportation and treatments. Depending on the studied scenario, the end of life configuration varies, and therefore, several logistic routes (to landfill, back to the manufacturer, etc.), transportations (truck, train) and waste treatments (land filling, recycling, reuse, etc.) are studied. It has been considered that the use phase does not generate impact because the waste container is maintenance-free.

In order to obtain results based on the real distribution and use of the container, transportation must be held into account and, as an average result from the manufacturer to the final user, $392 \mathrm{~km}$ of transportation will be used for the calculations. This distance is the average distance from Madrid to all cities with over 50,000 inhabitants in Spain. The same value is used for all studied scenarios and only the type of conveyance will differ to make the calculations totally comparable. The distance will refer to that travelled by the container already assembled from the manufacturing point to the city where its use phase will take place. The distance travelled by the plastic raw material is considered from its production place in Tarragona to the waste container manufacturer in Madrid $(547 \mathrm{~km})$, where as it was said, the material is transformed and the container is manufactured and assembled.

In all primary scenarios, we contemplated transportation in high load trucks (higher than 32 Tons according to Ecoinvent v3.0 database). In addition, in those scenarios where a closed loop supply chain system is analyzed, an inverse logistics process is necessary in order to take back the units to the manufacturing center. Therefore, this distance will be taken into account twice, considering the transportation back to the factory.

\subsection{Methodology}

This paper uses Recipe methodology, based on Ecoindicator99 and CML (Centrum voor Milieuwetenschappen) Leiden, to evaluate the impacts. Recipe combines midpoint and endpoint methodologies, making the results reliable and easier to comprehend. These 18 midpoint categories are calculated on the base of a cause-effect chain over the environment, which is weighted and later combined onto three endpoint categories. These three categories are: damage to human health, damage to ecosystems and damage to resource availability $[45,46]$. The calculation of each scenario of the unit under study will be carried out using the software EcoTool v4.0 [31]. This software collects data referred to as materials, processes, transports and all kind of transformations that might affect the environmental impact introduced by the user. These data feed from a database created starting from Ecoinvent v3.0 which is used by more than 6000 researchers using commercial life cycle assessment software [47]. Along with the study and because of its special relevance to the environment [48], a study on the unit carbon footprint is also carried out. This endpoint category has become of special importance of late with legal regulations controlling $\mathrm{CO}_{2}$ emissions [49]. These results will also be calculated using the same tool.

\subsection{Supply Chain Scenarios of the End of Life}

The end of life is defined as the number of transformations or processes that the whole unit and each of its parts separately will be part of, once its use phase is finished. Each supply chain scenario has been defined with a set of transports necessary to carry out all stages explained. At first, all scenarios will be comparable using high load trucks. These main conveyances will be used for the long transports of raw material and finished product. Transports from usage point to treatment locations near the location for non-closed loop scenarios will be calculated with a medium load truck (from 16 to 32 Tons according to Ecoinvent v3.0 database). In order to have enough information to determine how each material affects the environment depending on the end of life defined, four cases have been studied. All these scenarios use data extracted from the Ecoinvent v3.0 Database and the background of recycling efficiencies of European waste treatment plants [50].

The different scenarios studied in this paper are:

- SC1: Landfilling. 
- SC2: Standard recycling.

- SC3: Closed loop recycling of the thermoplastic parts.

- SC4: Closed loop with partial part reuse.

After studying SC1 to SC4 with road transportation, this last scenario will be recalculated replacing the transportation method chosen with freight rail conveyance to obtain SC4Train (Scenario 4 with Train) and compare the impact of the supply chain in the final product.

Over the same inventory, the end of life material management parameters are modified in order to be able to compare, when departing from a single place, the effects of each situation (see Table 2).

Table 2. End of life scenario definition.

\begin{tabular}{lcccccccc}
\hline & SC1 & SC1 & SC2 & SC2 & SC3 & SC3 & SC4 & SC4 \\
\hline & HDPE & Steel & HDPE & Steel & HDPE & Steel & HDPE & Steel \\
Recycling & $0 \%$ & $0 \%$ & $26.3 \%$ & $94 \%$ & $100 \%$ & $94 \%$ & $95 \%$ & $25 \%$ \\
Landfill & $100 \%$ & $100 \%$ & $38.1 \%$ & $6 \%$ & $0 \%$ & $6 \%$ & $0 \%$ & $0 \%$ \\
Incineration & $0 \%$ & $0 \%$ & $35.6 \%$ & $0 \%$ & $0 \%$ & $0 \%$ & $0 \%$ & $0 \%$ \\
Reuse & $0 \%$ & $0 \%$ & $0 \%$ & $0 \%$ & $0 \%$ & $0 \%$ & $5 \%$ & $75 \%$ \\
\hline
\end{tabular}

The SC1 studies the effects of landfilling the whole container. In this case, the unit does not go through any transformation and is directly landfilled in a dumpster in an average distance of $25 \mathrm{~km}$ away from the point of use (Figure 3).

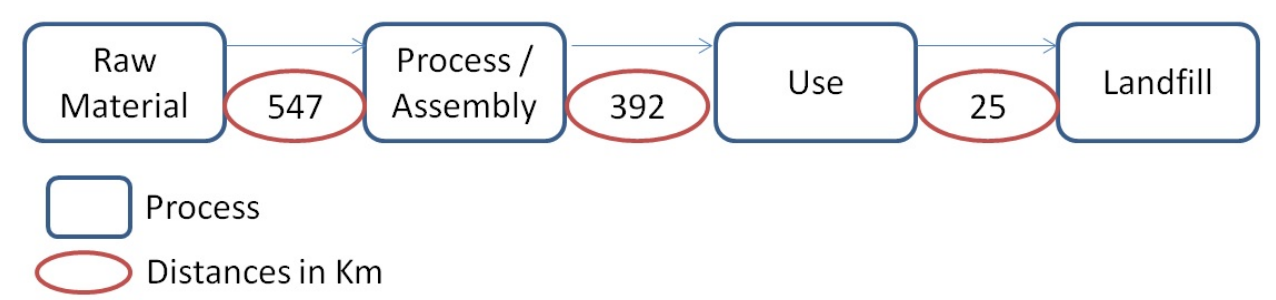

Figure 3. SC1 (Landfilling).

The SC2 calculates the environmental impact based in a standard recycling rate proposed by Plastics Europe [51], which gives data from the European plastic producers about waste management. This scenario combines different rates of landfilling, incineration and recycling depending on the material. Once the end of life of the product is reached, transportations to the waste treatment facility $(25 \mathrm{~km})$ will take place in a medium load capacity truck (Figure 4).

The SC3 comes after the problem observed in the previous situation. Thanks to being such a particular element, the $2400 \mathrm{~L}$ waste disposal container is managed wholly by the manufacturer. Once its use phase is over, it is recovered and processed along with other similar parts and never mixed with other elements. This implies a substantial increase in the supply chain complexity, but this problem can be overcome with the use of RFID tags to recover information about the life cycle (Figure 5).

Given the fact that material recovering and subsequent recycling is carried out in the original production center, it is possible to identify $100 \%$ of the parts but the transportations are doubled, and subsequently so is its impact. Therefore, for these SC3 thermoplastic materials, the recycling rate is $100 \%$, as they are recycled for internal use in the company. For the rest of the metallic parts used in the whole set, recycling rates are maintained as used in scenario 2. In the study of this SC3, transportation is held into account not only from the starting point to the point of duty, but also the way back to the factory where the separation will take part as explained in the subsection 2.2 System boundaries. 


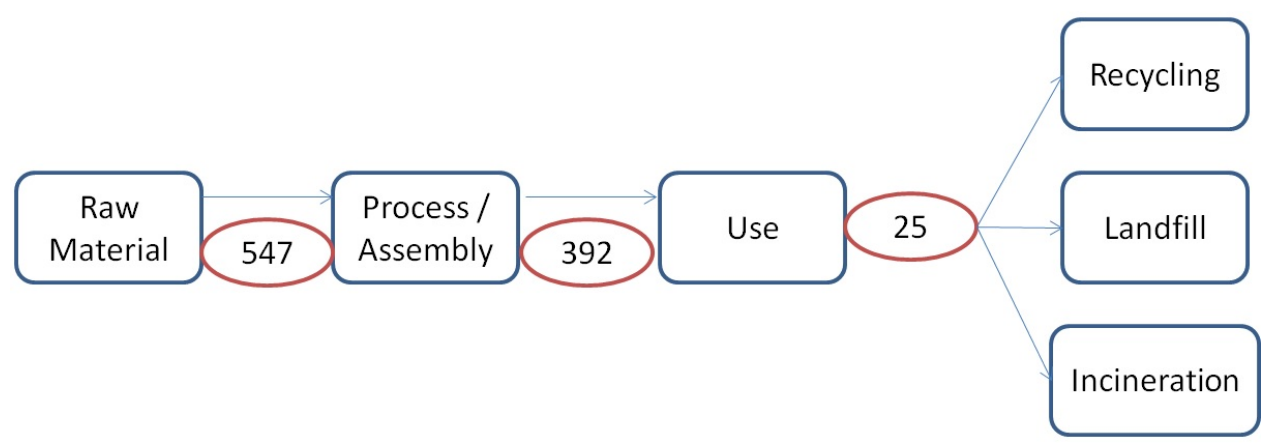

Figure 4. SC2 (Standard recycling).

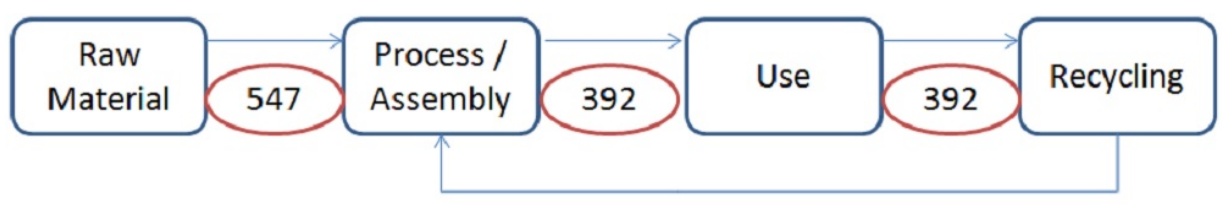

Figure 5. SC3 (Closed loop recycling of the thermoplastic parts).

Finally, the SC4 is a combination and extension of the previous closed loop philosophy. If in SC3 the exploitation of the thermoplastic materials is supposed, thanks to the supply chain management, then the next step is to present the direct reuse of some parts, subassemblies or even the whole container. This target requires once again the closed loop management of the containers once their use phase is at an end and their transportation to the manufacturing plant in Madrid. It is proposed, for SC4, that $5 \%$ of the containers are directly recovered for its reuse without any extra processes. Once disassembled, $70 \%$ of the metallic parts can be used once again. As for the rest of the parts and materials, they will all be recycled in the company (Figure 6).

The impact of the non-reutilized materials ( $95 \%$ of the whole) will be added to the end of life impact selected for this scenario. In this case, there is a recycling rate of $95 \%$ of the material with the addition of the impact generated by the milling process prior to the recycling. Later, the SC4 scenario is also calculated in SC4Train using railroad conveyance instead of traffic road to compare the direct impact of the transports.

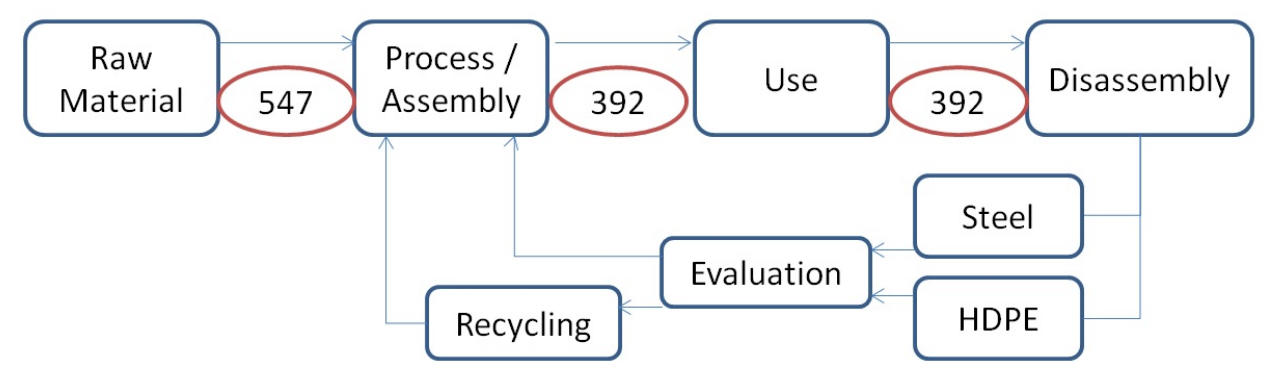

Figure 6. SC4 (Closed loop supply chain).

\section{Results}

Using the software EcoTool v4.0, calculation of the different scenarios applied to the full inventory of a $2400 \mathrm{~L}$ waste disposal container is done. First, the results for both Recipe and Carbon 
Footprint are presented in Table 3 with the different assessed scenarios distributed in columns. All these results are calculated with the same transport method (truck) in order to make the four studies totally comparable between each other, from raw material to disposal. After that, the SC4Train scenario will be studied to analyze how the environmental impact can be further reduced using train instead of truck transportation.

Table 3. LCA Results of the analyzed scenarios.

\begin{tabular}{lcccc}
\hline Method & SC1 & SC2 & SC3 & SC4 \\
\hline ReCiPe $(\mathrm{Pt})$ & 70.40 & 49.51 & 28.62 & 24.18 \\
kg eq. $\mathrm{CO}_{2}$ & 490.5 & 467.0 & 257.0 & 241.5 \\
\hline
\end{tabular}

Table 4 shows only the impact due to the supply chain of the of the end of life of the product. The results in SC1 and 2 are equal, and the same as SC3 and SC4 since they illustrate the difference between performing the treatment next to the using point, or transporting the product back to the manufacturing point.

Table 4. Disposal transportation results for the analyzed scenarios.

\begin{tabular}{lcccc}
\hline Method & SC1 & SC2 & SC3 & SC4 \\
\hline ReCiPe $(\mathrm{Pt})$ & 3.745 & 3.745 & 5.911 & 5.911 \\
kg eq. $\mathrm{CO}_{2}$ & 36.1 & 38.1 & 56.3 & 56.3 \\
\hline
\end{tabular}

SC1 calculates the impact of the direct landfilling of the container. It is clearly the most harmful scenario. Although it requires minimum material management and transportations, it is environmentally the least interesting. Compared to the first one, SC2, which calculates the impact of the standard recycling rates described by Plastics Europe, offers significant profit regarding Recipe punctuation and adds the same low complexity to the supply chain.

SC3 offers a substantial enhancement despite increasing the supply chain. This happens thanks to the integral recovering and recycling process done by the producer. This result proves a reduction of $56 \%$ Recipe impact and near $64 \%$ in kg eq. $\mathrm{CO}_{2}$ compared to SC2. SC4 offers the lowest results amongst all scenarios studied. In spite of having the same transports-related impacts, in this case, the global impact is reduced to a $66 \%$ cut in Recipe and $51 \%$ in $\mathrm{kg}$ eq. $\mathrm{CO}_{2}$ compared to the first scenario. However, the necessity of a complex supply chain management increases. For the SC 3 and $\mathrm{SC} 4$, the impact has also been calculated with transportations taking place on a freight train. Table 5 shows the impacts of all transportations (including raw materials). In the whole LCA of SC4Train the environmental impacts are decreased almost 15\%. The overall impacts of SC4Train are 20.77 ReCiPe points and $209.4 \mathrm{~kg}$ eq. $\mathrm{CO}_{2}$.

Table 5. Supply chain environmental impacts comparison of scenario SC4 and SC4 train.

\begin{tabular}{ccc}
\hline Method & SC4 Supply Chain Impact (truck) & SC4Train Supply Chain Impact \\
\hline $\operatorname{ReCiPe}(\mathrm{Pt})$ & 6.546 & 3.138 \\
kg eq. $\mathrm{CO}_{2}$ & 62.4 & 30.3 \\
\hline
\end{tabular}

\section{Conclusions}

Observing these results, it can be stated that, from the environmental point of view, the end of life supply chain management of a product modifies greatly the impact generated. 
Results have proven that the increase of impact due to the supply chain management in closed looped systems is compensated by the benefits that the supply chain creates, reducing the overall impact by allowing a better management of the disposed product.

The results claim that supply chain management is key to a reduction in the overall impact. In an undesirable scenario such as SC1, where the end of life is not carefully chosen, transports for the complete product are $5 \%$ in Recipe and $7.3 \%$ in carbon footprint. However, with all the manufacturing and recycling processes optimized, in SC4, transports are responsible for $24 \%$ Recipe and $23.3 \%$ carbon footprint ( $27 \%$ and $25.8 \%$ taking into account transports of the raw material), showing the importance of the supply chain in ecodesign products.

According to SC3, even with the increased supply chain related impact, it has proved beneficial regarding the whole environmental impact. This fact is conditioned to the usage of only one material in most of the parts, allowing a mistake-free material identification in order to maximize the recycling rates. This fact was pursued from the very starting point of the design process. It is proven that environmental aspects must be in sight from the first stages of the product development. This will help the choice between solutions that will affect later the life cycle analysis.

SC4 generated the best results in terms of environmental impact and when the change to freight rail transports were studied, significant reductions in the impact were proven. Recipe impact due to transportations was reduced by a $52.06 \%$ and $51.5 \%$ carbon footprint. This means that enhancing the end of life treatment, recycling ratios, etc., must be accompanied by an adequate selection of the closed loop supply chain transportation methods.

It is hereby proven that, from the environmental point of view, the impact derived from the end of life management carried out of a $2400 \mathrm{~L}$ waste disposal container, is highly sensitive to the logistics chosen for its different stages. Closed loop management is desirable when possible since, despite the complexity added to the supply chain, it proves beneficial from the sustainability point of view and can be applied in a wide range of industries. Future lines of work include focusing on the other two pillars of sustainability (economic and social) to analyze the influence of these closed loop supply chain strategies.

Acknowledgments: The research in this paper has been developed by members of the I+AITIIP (DGA-T39) research group recognized by the Regional Government of Aragon (DGA) (FSE-EU).

Author Contributions: José Eduardo Galve is a Ph.D. student responsible for analyzing and calculating the different scenarios using the environmental assessment software EcoTool v4.0, all mentioned in collaboration with Daniel Elduque, a researcher in the field of environmental impact and codirector of the doctoral thesis. Carlos Javierre is codirector of the doctoral thesis and defined the scenarios with the first draft of the essay, reviewing and guiding the manuscript writing process. Carmelo Pina helped analyzing the scenarios and with its conclusions.

Conflicts of Interest: The authors declare no conflict of interest.

\section{Abbreviations}

The following abbreviations are used in this manuscript:

LCA: Life Cycle Assessment

SC: Scenario

EOL: End Of Life

RFID: Radio Frequency IDentification

HDPE: High Density Polyethylene

\section{References}

1. Shi, J.; Xiao, T. Service investment and consumer returns policy in a vendor-managed inventory supply chain. J. Inst. Manag. Optim. 2015, 11, 439-459.

2. Chin, T.A.; Tat, H.H.; Sulaiman, Z. Green supply chain management, environmental collaboration and sustainability performance. Int. J. Oper. Prod. Manag. 2015, 26, 695-699. 
3. Litman, T.; Burwell, D. Issues in sustainable transportation. Int. J. Oper. Prod. Manag. 2008, 6, $331-347$.

4. Nguyen, L.; Cafferty, K.; Searcy, E.; Spatari, S. Uncertainties in life cycle greenhouse gas emissions from advanced biomass feedstock logistics supply chains in Kansas. Energies 2014, 7, 7125-7146.

5. Kolak, O.I.; Feyzioğlu, O.; Birbil, Ş.İ.; Noyan, N.; Yalçindağ, S. Using emission functions in modeling environmentally sustainable traffic assigment policies. J. Ind. Manag. Optim. 2013, 9, 341-363.

6. Zailani, S.; Govindan, K.; Iranmanesh, M.; Shaharudin, M.R.; Chong, Y.S. Green innovation adoption in automotive supply chain: The Malaysian case. J. Clean Prod. 2015, 108, 1115-1122.

7. Marletto, G.; Sillig, C.T. Environmental impact of Italian canned tomato logistics: National vs. regional supply chains. J. Transp. Geogr. 2014, 34, 142-149.

8. Yazan, D.M.; Petruzelli, A.M. Analyzing the environmental impact of transportation in reengineered supply chains: A case study of a leather upholstery company. Transport. Res. 2011, 16, 335-340.

9. Accorsi, R.; Versari, L.; Manzini, R. Glass vs. plastic: Life cycle assessment of extra-virgin olive oil bottles across global supply chains. Sustainbability 2015, 7, 2818-2840.

10. Longo, F. Sustainable supply chain design: An application example in local business retail. Simulation 2012, $88,1484-1498$.

11. Villanueva, R.; García, J.L.; Cortes, G.; Romero, J.; Jiménez, E.; Blanco, J. Impact of suppliers' green attributes in corporate image and financial profit: Case maquiladora industry. Int. J. Adv. Manuf. Tech. 2015, 80, 1277-1296.

12. García-Arca, J.; Prado-Prado, J.C. Packaging design model from a supply chain approach. Supply Chain Manag. 2008, 13, 375-380.

13. Olander-Roese, M.; Nilsson, F. Competitive advantages through packaging design? prepositions for supply chain effectiveness and efficiency. In Proceedings of the International Conference on Engineering Design, ICED 2009, Stanford University, Stanford, CA, USA, 24-27 August 2009.

14. Jahre, M.; Hatteland, C.J. Packages and physical distribution-Implications for integration and standardization. Int. J. Phys. Distrib. Logist Manag. 2004, 34, 123-139.

15. Nilsson, F.; Fagerlund, M.; Körner, J. Globally standardised versus locally adapted packaging: A case study at Sony Ericsson Mobile Communications AB. Int. J. Retail Distrib. Manag. 2013, 41, 396-414.

16. Hellström, D.; Nilsson, F. Logistics-driven packaging innovation: A case study at IKEA. Int. J. Retail Distrib. Manag. 2011, 39, 638-657.

17. García-Arca, J.; Gonzalez-Portela Garrido, A.T.; Prado-Prado, J.C. "Packaging Logistics" for improving performance in supply chains: The role of meta-standards implementation. Production 2016, doi:10.1590/0103-6513.184114.

18. García-Arca, J.; Prado-Prado, J.C.; Gonzalez-Portela Garrido, A.T. "Packaging logistics": Promoting sustainable efficiency in supply chains, physical distribution-Implications for integration and standardization. Int. J. Pgys. Distrib. Logist Manag. 2014, 44, 325-346.

19. Svanes, E.; Vold, M.; Møller, H., Pettersen, M.K.; Larsen, H.; Hanssen, O.J. Sustainable packaging design: A holistic methodology for packaging design. Packag. Technol. Sci. 2010, 23, 161-175.

20. Abbasi, M.; Nilsson, F. Developing environmentally sustainable logistics Exploring themes and challenges from a logistics service providers' perspective. Transport Res. Part D-Transport Environ. 2016, 46, 273-283.

21. Abbasi, M.; Nilsson, F. Themes and challenges in making supply chains environmentally sustainable. Supply Chain Manag. 2012, 17, 517-530.

22. Andrae, A.; Xia, M.; Zhang, J.; Tang, X,T. Practical Eco-Design and Eco-Innovation of Consumer Electronics-the Case of Mobile Phones. Challenges 2016, 7, 3.

23. Leigh, M.; Li, X. Industrial ecology, industrial symbiosis and supply chain environmental sustainability: A case study of a large UK distributor. J. Clean Prod. 2015, 106, 632-643.

24. De Schepper, M.; van den Heede, P; van Driessche, I.; de Belie, N. Life Cycle Assessment of Completely Recyclable Concrete. Materials 2014, 7, 6010-6027.

25. Martínez, E.; Sanz, F.; Pellegrini, S.; Jímenez , E.; Blanco, J. Life-cycle assessment of a 2-MW rated power wind turbine: CML method. Int. J. Life Cycle Assess. 2008, 14, 52-63.

26. Pina, C.; Elduque, D.; Javierre, C.; Martínez, E.; Jiménez, E. Influence of mechanical design on the evolution of the environmental impact of an induction hob. Int. J. Life Cycles Assess. 2015, 20, 937-946.

27. Elduque, D.; Javierre, C.; Pina, C.; Martínez, E.; Jiménez, E. Life cycle assessment of a domestic induction hob: Electronic boards. J. Clean Prod. 2014, 76, 74-84. 
28. Rajendran, S.; Hodzic, A.; Scelsi, L.; Hayes, S.; Scoutis, C.; AlMa'adeed, M.; Kahraman, R. Plastics recycling: Insights into life cycle impact assessment methods. Plast Rubber Compos. 2013, 42, 1-10.

29. Rives, J.; Rieradevall, J.; Gabarrell, X. LCA comparison of container systems in municipal solid waste management. Waste Manag. 2010, 30, 949-957.

30. Guinée, J.B. Handbook on Life Cycle Assessment Operational Guide to the ISO Standards. Int. J. Life Cycle Assess. 2013, 7, 311-313.

31. Camañes, V.; Elduque, D.; Javierre, C.; Fernández, Á. The influence of different recycling scenarios on the mechanical design of an LED weatherproof light fitting. Materials 2014, 7, 5769-5788.

32. Fernández, Á.; Javierre, C.; González, J.; Elduque, D.T. Development of thermoplastic material food packaging considering technical, economic and environmental criteria. J. Biobased Mater. Bioenergy 2013, 7, 176-183.

33. Kim, H.C.; Wallington, T.J. Plastics life-cycle energy and greenhouse gas emission benefits of lightweighting in automobiles: Review and harmonization. Esthag 2013, 47, 6089-6097.

34. Morelli, J. Environmental Sustainability: A definition for environmental professionals. J. Environ. Sustain. 2011, 1, 2.

35. Elduque, A.; Javierre, C.; Elduque, D.; Fernández, Á. LCI databases sensitivity analysis of the environmental impact of the injection molding process. Sustainability 2015, 108, 3792-3800.

36. Quiang, Q. The closed-loop supply chain network with competition and design for remanufactureability. J. Clean. Prod. 2015, 105, 348-356.

37. Govindan, K.; Soleimani, H. A review of reverse logistics and closed-loop supply chains: A Journal of Cleaner Production focus. J. Clean. Prod. 2016. doi:10.1016/j.jclepro.2016.03.126.

38. Kerr, W.; Ryan, C. Eco-efficiency gains from remanufacturing: A case study of photocopier remanufacturing at Fuji Xerox Australia. J. Clean. Prod. 2001, 9, 75-81.

39. Wang, Y.; Wallace, S.W.; Shen, B.; Choi, T. Service supply chain management: A review of operational models. Eur. J. Oper. Res. 2015, 247, 685-698.

40. Zhou, W.; Piramuthu, S. Remanufacturing with RFID item-level information: Optimization, waste reduction and quality improvement. Int. J. Prod. Econ. 2013, 145, 647-657.

41. Mota, B.; Gomes, M.I.; Carvalho, A.; Barbosa-Povoa, A.P. Towards supply chain sustainability: Economic, environmental and social design and planning. J. Clean Prod. 2015, 105, $14-27$.

42. Aisa, J.; Javierre, C.; de La Serna, J.A. An example of simulation tools use for large injection moulds design: The CONTENUR ${ }^{\mathrm{TM}} 24001$ solid waste container. J. Mater. Process Tech. 2006, 175, 15-19.

43. Contenur. Products. Available online: http://www.contenur.com/en/products (accessed on 26 May 2016).

44. Lupo, E.; Moroni, M.; La Marca, F.; Fulco, S.; Pinzi, V. Investigation on an innovative technology for wet separation of plastic wastes. Waste Manag. 2016, 51, 3-12.

45. Goedkoop, M.; Oele, M.; Leijting, J.; Ponsioen, T.; Meijer, E. SimaPro 8. Introduction into LCA; PRé Consultants: Amersfoort, The Netherlands, 2013.

46. Jones, S.; Anya, A.; Stacey, N.; Weir, L. A Life-cycle Approach to Improve the Sustainability of Rural Water Systems in Resource-Limited Countries. Challenges 2012, 247, 233-260.

47. Weidema, B.P.; Bauer, C.; Hischier, R.; Mutel, C.; Nemecek, T.; Reinhard, J.; Vadenbo, C.O.; Wernet, G. Data quality guideline for the ecoinvent database version 3.0. Ecoinvent Report 1(v3.0). In Overview and Methodology; Frischknecht, R., Jungbluth, N., Eds.; Swiss Centre for Life Cycle Inventories: St. Gallen, Switzerland, 2013.

48. Knight, K.W.; Schor, J.B. Economic Growth and Climate Change: A Cross-National Analysis of Territorial and Consumption-Based Carbon Emissions in High-Income Countries. Sustainability 2014, 6, 3722-3731.

49. Spanish Government. Real Decreto Español 163/2014, de 14 de marzo, por el que se crea el registro de huella de carbono, compensación y proyectos de absorción de dióxido de carbono. In Boletín Oficial del Estado; Ministry of Agriculture, Food and Environment: Madrid, Spain, 2014. 
50. International Electrotechnical Commission. IEC/TR 62635. Guidelines for End-of-life Information Provided by Manufacturers and Recyclers and for Recyclability Rate Calculation of Electrical and Electronic Equipment; International Electrotechnical Commission: Geneva, Switzerland, 2015.

51. Plastics Europe, Association of Plastics Manufacturers. An analysis of European latest plastics production, demand and waste data. In Plastics - the Facts 2014/2015; Association of Plastics Manufacturers: Brussels, Belgium, 2015.

(C) 2016 by the authors; licensee MDPI, Basel, Switzerland. This article is an open access article distributed under the terms and conditions of the Creative Commons Attribution (CC-BY) license (http://creativecommons.org/licenses/by/4.0/). 